\title{
Article
}

\section{Alpha2 agonist dexmedetomidine may reduce duration of delirium in critically ill adults}

Hill, James Edward, sange, chandbi and Clegg, Andrew

Available at https://clok.uclan.ac.uk/33843/

Hill, James Edward orcid iconORCID: 0000-0003-1430-6927, sange, chandbi and Clegg, Andrew orcid iconORCID: 0000-0001-8938-7819 (2020) Alpha2 agonist dexmedetomidine may reduce duration of delirium in critically ill adults. Evidence-Based Nursing . ISSN 1367-6539

It is advisable to refer to the publisher's version if you intend to cite from the work.

For more information about UCLan's research in this area go to http://www.uclan.ac.uk/researchgroups/ and search for <name of research Group>.

For information about Research generally at UCLan please go to http://www.uclan.ac.uk/research/

All outputs in CLoK are protected by Intellectual Property Rights law, including Copyright law. Copyright, IPR and Moral Rights for the works on this site are retained by the individual authors and/or other copyright owners. Terms and conditions for use of this material are defined in the policies page.

\section{CLoK}

Central Lancashire online Knowledge www.clok.uclan.ac.uk

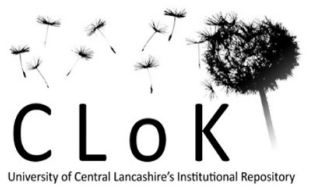




\section{Category:}

\section{Study type:}

Author's declarative title: Alpha ${ }_{2}$ agonist dexmedetomidine may reduce duration of delirium in critically ill adults.

Commentary on: Burry L, et al. Pharmacological interventions for the treatment of delirium in critically ill adults. Cochrane Database of Systematic Reviews 2019, Issue 9. Art. No.: CD011749. DOI: 10.1002/14651858.CD011749.pub2.

\section{Commentary \\ Implications for practice and research}

- Alpha 2 agonist dexmedetomidine may reduce duration of delirium.

- Cholinesterase inhibitor rivastigmine may prolong the duration of delirium and length of intensive care.

- Future research should ensure that important clinical outcomes are reported such as symptom management.

\section{Context}

Delirium is a multifaceted neurocognitive indication of an underlying medical condition (1).

It frequently occurs in critically ill patients and can have substantial negative consequences with increased mortality and intensive care unit (ICU) length of stay (2). Uncertainty remains around the effectiveness of pharmacological interventions for the treatment of delirium within ICU (3). This Cochrane systematic review aims to examine the effectiveness of pharmacological interventions for treating delirium in critically ill adults with a confirmed or documented high risk of delirium (3).

\section{Methods}

A comprehensive peer-reviewed search of nine electronic databases was carried out from date of inception to 21 March 2019, supplemented by searches of systematic reviews and grey literature. Only Randomized Controlled Trials (RCTs) or quasi RCTs which compared the effectiveness of any pharmacological intervention to another pharmacological/nonpharmacological intervention or placebo in critically ill adults were included. A robust screening, data extraction and quality assessment (Cochrane risk of bias criteria and overall summary quality using GRADE) was undertaken by two independent reviewers with arbitration by a third reviewer. Evidence synthesis was undertaken using a Pairwise random effects meta-analysis and a network metaanalysis. 


\section{Findings}

Fourteen trials with 1,844 participants examining six different drug classes (antipsychotics, alpha2 agonists, statins, opioids, serotonin antagonists and cholinesterase inhibitors) for treating delirium in critically ill adults were included in the review. Of the 14 trials, nine were judged to be of low risk of bias with the overall quality of the included studies ranging from low to high.

Only two studies showed any statistically significant effect from the active treatment compared to placebo in pairwise comparisons. Although one study (71 participants, moderate quality evidence) found a reduction in delirium duration from dexmedetomidine (alpha ${ }_{2}$ antagonist), another study (114 participants, moderate quality evidence) reported an increase in duration of delirium and length of intensive care stay following treatment with cholinesterase inhibitors. None of the other drugs showed a statistically significant change in delirium duration, deliriumfree and coma-free days, days with coma, and length of stay. Limited evidence prevented NMAs of long-term cognitive outcomes or mortality.

The limited benefit of the six drug classes compared to placebo were emphasised through a network meta-analysis (NMA). Despite alpha2 antagonists being ranked in the NMA as the best in in reducing the duration of mechanical ventilation and length of stay the reduction was not statistically significant.

\section{Commentary}

Looking at the quality of the review using the Amstar2 tool, this review is of high quality and provides an accurate and comprehensive summary of the results of the available studies that address the question of interest.

Despite the common use of pharmacological interventions in managing delirium (4) only the alpha2 agonist dexmedetomidine was found to have a small statistically significant effect in duration of delirium compared to placebo. Furthermore, no other pharmacological intervention had any effect on delirium duration, or any other secondary outcomes reported in this review. Concerningly cholinesterase inhibitor was associated with harms and as such, guidelines suggest against its use for treatment of ICU delirium (3). Although, reported adverse events in the included studies were similar between the pharmacological intervention and placebo it is important to note that these two findings of alpha2 agonist dexmedetomidine and cholinesterase inhibitor were from only one relatively small study each and these findings may change with additional new evidence. There is a growing interest in this area, currently 10 studies which are ongoing and six which are awaiting classification have been identified to have large sample sizes, which may change the estimations of effect identified within this review.

As well as these ongoing trials, further research should ensure that important clinical outcomes are reported such as symptom management, for example stopping treatment interferences and treating agitation. Wherever possible core outcome sets should be used. It is also important that future research ensures reporting possibly confounding variables such as early mobilization and physical restraints. 


\section{References}

1. Lawlor PG, Bush SH. Delirium diagnosis, screening and management. Curr Opin Support Palliat Care. 2014;8(3):286-95.

2. Salluh JI, Soares M, Teles JM, Ceraso D, Raimondi N, Nava VS, et al. Delirium epidemiology in critical care (DECCA): an international study. Crit Care. 2010;14(6):R210.

3. Burry L, Hutton B, Williamson DR, Mehta S, Adhikari NK, Cheng W, et al.

Pharmacological interventions for the treatment of delirium in critically ill adults. Cochrane Database Syst Rev. 2019;9:CD011749.

4. Burry LD, Williamson DR, Mehta S, Perreault MM, Mantas I, Mallick R, et al. Delirium and exposure to psychoactive medications in critically ill adults: A multi-centre observational study. J Crit Care. 2017;42:268-74.

\section{Commentator details}

Name: James Edward Hill

Affiliation: University of Central Lancashire

Correspondence address:

University of Central Lancashire,

Preston,

Lancashire

PR1 2HE

Email: Jehill1@uclan.ac.uk

\section{Competing interests}

I have no conflicts of interest with any aspect of this publication.

Acknowledgements: This report is independent research funded by the National Institute for Health Research Applied Research Collaboration North West Coast (ARC NWC). The views expressed in this publication are those of the author(s) and not necessarily those of the National Institute for Health Research or the Department of Health and Social Care. 